Pacific Journal of Mathematics

DEGENERATE ELLIPTIC EQUATIONS

Moos RedHeFFER AND ERNSt Gabon STRAus 


\section{DEGENERATE ELLIPTIC EQUATIONS}

R. M. Redheffer and E. G. Straus

Let $B$ denote a region of Euclidean $n$ space, with points $x=$ $\left(x_{1}, x_{2}, \cdots, x_{n}\right) \in B$, and let $u=u(x)$ be such that each partial derivative, $u_{i}$, is a differentiable function of $x$. If

$$
\sum a_{i j}(x) u_{i j}+g(|\operatorname{grad} u|) \geqq 0 \text { and }\left(a_{i j}\right) \geqq 0,
$$

then appropriate conditions on $\left(a_{i j}\right)$ and on the function $g$ ensure that $u$ satisfies the maximum principle. That is, the inequality $u \leqq m$ on $\partial S$ implies $u \leqq m$ in $S$ for every constant $m$ and every compact set $S \subset B$.

For example: Let $g(s)$ be positive, continuous and increasing for $s>0$, and let

$$
\int_{0}^{1} \frac{d s}{g(s)}=\infty
$$

Suppose there exists a function $c(x) \in C^{(2)}$ such that, for $x \in S$,

$$
\inf \sum a_{i j}(x) c_{i}(x) c_{j}(x)>0, \quad \text { inf } \sum a_{i j}(x) c_{i j}(x)>-\infty \text {. }
$$

Then the maximum principle holds [1].

If $g(s)=o(s)$ the weaker condition [2]

$$
\inf \sum a_{i j}(x) c_{i j}(x)>0
$$

suffices; for example, let $\left(a_{i j}\right)$ be continuous and nonvanishing. Even when $g(s)=o(s)$, the maximum principle fails if $\left(a_{i j}\right)$ vanishes at one point. But if $g(s)=0$, a great many zeros can be allowed, and that is the reason for this note.

We shall establish:

THEOREM 1. Let $u$ be a $C^{(2)}$ solution of $\sum a_{i j}(x) u_{i j} \geqq 0$, where $\left(a_{i j}\right) \geqq 0$. Suppose that the set of points $x \in B$ where $\left(a_{i j}\right)=(0)$ has no interior points. Then $u$ satisfies the maximum principle.

The proof depends on the following lemma.

Lemma 1. Let $u \in C^{(2)}$ in a bounded region $B$, and let $u \in C^{(0)}$ be in the closure, $\bar{B}$, of $B$. Let $\widetilde{B}$ be a dense subset of $B$. If $\sup _{x \in B} u>\sup _{x \in \partial B} u$ then there exists a quadratic polynomial $\theta(x)$ with arbitrarily small coefficients so that $\left(\theta_{i j}\right)>0$ and $u+\theta$ attains

Received April 19, 1963. 
its maximum in $\widetilde{B}$.

Proof. Choose $h>0$ so small that $\sup _{\partial_{B}}\left(u+h|x|^{2}\right)<\sup _{B}\left(u+h|x|^{2}\right)$. Then the function $v=u+h|x|^{2}$ attains its maximum at a point $x_{0} \in B$. The function $w=v-(h / 2)\left|x-x_{0}\right|^{2}$ has $x_{0}$ as a unique maximum point and satisfies $\left(w_{i j}\left(x_{0}\right)\right)=\left(v_{i j}\left(x_{0}\right)\right)-h I \leqq-h I<0$ and therefore $\left(w_{i j}(x)\right)<0$ in a neighborhood $N:\left|x-x_{0}\right|<\delta$. The surface $S: z=$ $w(x)$ is strictly concave for $x \in N$, while for $x \notin N$ we have $w(x) \leqq$ $w\left(x_{0}\right)-h \delta^{2} / 2$. Since the tangent plane of $S$ at $x_{0}$ is horizontal and its direction varies continuously in $N$, there is a neighborhood $N_{1} \subset N$ of $x_{0}$ so that tangent plane of $S$ at any point $x_{1} \in N_{1}$ lies entirely above $S$, except at the point $x_{1}$ itself.

Choose $x_{1} \in N_{1} \cap \widetilde{B}$. Then function $w(x)-w\left(x_{1}\right)-\sum_{i} w_{i}\left(x_{1}\right)\left(x^{i}-x_{1}^{i}\right)$ is negative everywhere in the closure of $B$ except at $x_{1}$. Thus, the function

$$
\theta(x)=h|x|^{2}-\frac{1}{2} h\left|x-x_{0}\right|^{2}-\sum_{i} w_{i}\left(x_{1}\right)\left(x^{i}-x_{1}^{i}\right)
$$

has the desired properties, since $\left(\theta_{i j}\right)=h I>0$ and we can choose $h$ and $w_{i}\left(x_{1}\right)$ arbitrarily small.

Proof of Theorem 1. Let $\widetilde{B}$ be the set for which $\left(a_{i j}\right) \neq 0$. If for some compact subset $S$ of $B$ we would have $u$ attain its maximum in the interior of $S$, then according to Lemma 1 we could choose $\theta$ so that $u+\theta$ attained its maximum at a point of $\widetilde{B} \cap S$. This leads to a contradiction since $\left(u_{i j}\right) \leqq-\left(\theta_{i j}\right)<0$ at this point.

The foregoing proof makes essential use of the condition $u \in C^{(2)}$. We now assume only that $u$ is differentiable.

A singularity is a point where one or more of the following undesirable things happen:

(1) Some derivative $u_{i}$ fails to be differentiable.

(2) The differential inequality $\sum a_{i j}(x) u_{i j} \geqq 0$ fails.

(3) The matrix $\left(a_{i j}\right)=(0)$.

(4) The condition $\left(a_{i j}\right) \geqq 0$ fails.

A "smooth surface" is a surface of form $\phi(x)=0$, where $\phi \in C^{(2)}$ and $\operatorname{grad} \phi \neq 0$. We can now state:

THeOREm 2. Let $u$ be differentiable for $x \in B$, and let the singularities be contained in the union of countably many smooth surfaces. Then $u$ satisfies the maximum principle.

The proof again depends on a small modification of $u$ which moves the maximum outside the surfaces of singularities. 
Lemma 2. Let $u$ be differentiable in the bounded region $B$ and continuous in the closure of $B$. Let $\phi^{(k)}(x)$ be twice differentiable with bounded $\phi_{i j}^{(k)}$ and $\operatorname{grad} \phi^{(k)}(x) \neq 0$ in $B ; k=1,2, \cdots$.

If $\sup _{B} u>\sup _{\partial_{B}} u$ then there exists a function $\theta(x)$ twice differentiable in $B$ so that $\theta, \theta_{i}, \theta_{i j}$ are arbitrarily small in $B$; $\left(\theta_{i j}\right)>0$ and $u+\theta$ attains its maximum at a point of $B$ which does not lie on any surface $\phi^{(k)}(x)=0$.

Proof. We write $\theta=h|x|^{2}+\sum c_{k} \phi^{(k)}(x)$ where $h>0$ is chosen so small that $\sup _{B}\left(u+h|x|^{2}\right)>\sup _{\partial B}\left(u+h|x|^{2}\right)+h$ and the $c_{k}$ are determined successively as follows. Set $\theta^{(0)}=h|x|^{2}$ and $\theta^{(n)}=$ $h|x|^{2}+\sum_{k=1}^{n} c_{k} \phi^{(k)}(x)$. If $u+\theta^{(n)}$ does not attain its maximum on $\phi^{(n+1)}(x)=0$ then we set $c_{n+1}=0$. If $u+\theta^{n}$ does attain its maximum on $\phi^{(n+1)}(x)=0$ then we choose $c_{n+1}>0$ but so small that

(1) $c_{n+1}\left(\phi_{i j}^{(n+1)}(x)\right)<\frac{h}{2^{n+1}} I$,

(2) $c_{n+1}\left|\phi^{(n+1)}(x)\right|<\frac{1}{2^{n+1}}\left(\max _{B}\left(u+\theta^{(k)}\right)-\max _{\phi^{(k)}=0}\left(u+\theta^{(k)}\right)\right.$, $k=1,2, \cdots, n$,

(3) $\quad c_{n+1}\left|\phi^{(n+1)}(x)\right|<\frac{h}{2^{n+1}}, \quad c_{n+1}\left|\phi_{i}^{(n+1)}(x)\right|<\frac{h}{2^{n+1}}$

for all $x \in B$.

Since $\operatorname{grad} \phi^{(n+1)} \neq 0$ it follows that $u+\theta^{(n+1)}$ does not attain its maximum on $\phi^{(n+1)}(x)=0$ while condition (2) guarantees that it also does not attain its maximum on $\phi^{(k)}(x)=0, k=1, \cdots, n$. Conditions (1) and (3) guarantee the convergence of $\theta$ to a twice differentiable function which together with its first and second derivatives is small for small choices of $h$. By condition (2) $u+\theta$ does not attain its maximum on any surface $\phi^{(k)}(x)=0$, but since $|\theta|<h|x|^{2}+h$ it attains its maximum in $B$. Finally, condition (1) makes

$$
\left(\theta_{i j}\right)>2 h I-\sum c_{k}\left(\left|\phi_{i j}^{(k)}\right|\right)>2 h I-\sum \frac{h}{2^{k}} I=h I .
$$

The proof of Theorem 2 now proceeds exactly as the proof of Theorem 1.

Combining the ideas of Theorems 1 and 2 we obtain the following generalization of Theorem 1 .

THEOREM 3. Let $u$ be differentiable in $B$, and have continuous second derivatives except on the union of countably many smooth surfaces. If the conditions

$$
\sum a_{i j}(x) u_{i j} \geqq 0, \quad\left(a_{i j}\right) \geqq 0, \quad\left(a_{i j}\right) \neq(0)
$$


hold on a dense subset of $B$, then $u$ satisfies the maximum principle.

Proof. According to Lemma 2 we can find a function, $\theta$ so that $\left(\theta_{i j}\right)>0$ and $u+\theta$ attains its maximum at a point of continuity of $\left(u_{i j}\right)$. The construction in the proof of Lemma 1 therefore yields a function $\tilde{\theta}$ so that $u+\theta+\widetilde{\theta}$ attains its maximum at a point of the set of points in $B$ at which $\left(a_{i j}\right) \neq 0$, and $\left(\theta_{i j}\right)+\left(\tilde{\theta}_{i j}\right)>0$.

It is fairly obvious that these theorems are in many ways best possible. Certainly if the set at which $\left(a_{i j}\right)=0$ has interior points the maximum principle fails.

The integral of a singular (Cantor) function satisfies $u_{11}=0$ except at points of the Cantor set, but it need not satisfy the maximum principle. Thus the restriction to a denumerable number of surfaces of singularities in Theorems 2 and 3 cannot be substantially relaxed.

\section{REFERENCES}

1. R. M. Redheffer, An extension of certain maximum principles, Monatsh. f. Math., 62 (1962), 56-75.

2. ——, Bemerkungen über Monotonie und Fehlerabschätzung bei nichtlinearen partiellen Differentialgleichungen, Arch. Rat. Mech. and Anal., 10 (1962), 427-457.

UNIVERSity of CALIFORNIA, Los ANGELES 


\section{PACIFIC JOURNAL OF MATHEMATICS}

\section{EDITORS}

Robert Osserman

Stanford University

Stanford, California

M. G. Arsove

University of Washington

Seattle 5 , Washington
J. DugundjI

University of Southern Califorma: Los Angeles 7, California

Lowell J. Paige

University of California

Los Angeles 24, California

\section{ASSOCIATE EDITORS}

E. F. BECKENBACH

B. H. NeumanN

F. WOLF

K. YosIDA

\section{SUPPORTING INSTITUTIONS}

UNIVERSITY OF BRITISH COLUMBIA

CALIFORNIA INSTITUTE OF TECHNOLOGY

UNIVERSITY OF CALIFORNIA

MONTANA STATE UNIVERSITY

UNIVERSITY OF NEVADA

NEW MEXICO STATE UNIVERSITY

OREGON STATE UNIVERSITY

UNIVERSITY OF OREGON

OSAKA UNIVERSITY

UNIVERSITY OF SOUTHERN CALIFORNIA
STANFORD UNIVERSITY

UNIVERSITY OF TOKYO

UNIVERSITY OF UTAH

WASHINGTON STATE UNIVERSITY

UNIVERSITY OF WASHINGTON

AMERICAN MATHEMATICAL SOCIETY CALIFORNIA RESEARCH CORPORATION SPACE TECHNOLOGY LABORATORIES NAVAL ORDNANCE TEST STATION 


\section{Pacific Journal of Mathematics}

\section{Vol. 14, No. 1 \\ May, 1964}

Richard Arens, Normal form for a Pfaffian .........................

Charles Vernon Coffman, Non-linear differential equations on cones in Banach

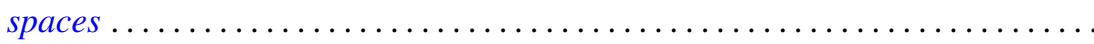

Ralph DeMarr, Order convergence in linear topological spaces ..............

Peter Larkin Duren, On the spectrum of a Toeplitz operator ................

Robert E. Edwards, Endomorphisms of function-spaces which leave stable all

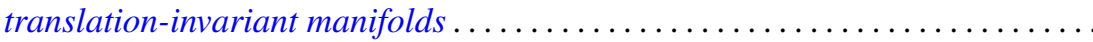

Erik Maurice Ellentuck, Infinite products of isols . . . . . . . . . . . . . . . . 49

William James Firey, Some applications of means of convex bodies . . . . . . . . 53

Haim Gaifman, Concerning measures on Boolean algebras ............. 61

Richard Carl Gilbert, Extremal spectral functions of a symmetric operator. . . . . . 75

Ronald Lewis Graham, On finite sums of reciprocals of distinct nth powers ..... 85

Hwa Suk Hahn, On the relative growth of differences of partition functions ...... 93

Isidore Isaac Hirschman, Jr., Extreme eigen values of Toeplitz forms associated

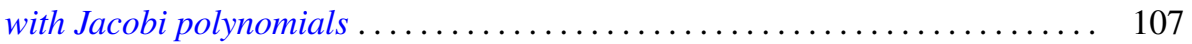

Chen-jung Hsu, Remarks on certain almost product spaces . . . . . . . . . . . 163

George Seth Innis, Jr., Some reproducing kernels for the unit disk . . . . . . . . . 177

Ronald Jacobowitz, Multiplicativity of the local Hilbert symbol . . . . . . . . . . . 187

Paul Joseph Kelly, On some mappings related to graphs ................. 191

William A. Kirk, On curvature of a metric space at a point . . . . . . . . . . . . 195

G. J. Kurowski, On the convergence of semi-discrete analytic functions . . . . . . . 199

Richard George Laatsch, Extensions of subadditive functions . . . . . . . . . . . 209

V. Marić, On some properties of solutions of $\Delta \psi+A\left(r^{2}\right) X \nabla \psi+C\left(r^{2}\right) \psi=0 \ldots 217$

William H. Mills, Polynomials with minimal value sets . . . . . . . . . . . 225

George James Minty, Jr., On the monotonicity of the gradient of a convex

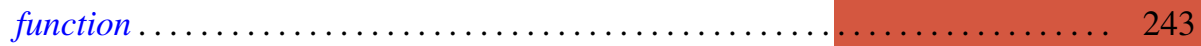

George James Minty, Jr., On the solvability of nonlinear functional equations of 'monotonic' type ................................... 249

J. B. Muskat, On the solvability of $x^{e} \equiv e(\bmod p) \ldots \ldots \ldots \ldots \ldots \ldots \ldots \ldots . \ldots \ldots$

Zeev Nehari, On an inequality of $P . R$. Bessack ................... 261

Raymond Moos Redheffer and Ernst Gabor Straus, Degenerate elliptic

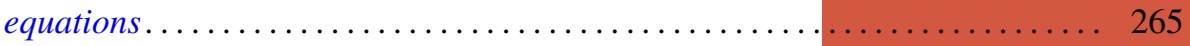

Abraham Robinson, On generalized limits and linear functionals . . . . . . . . . 269

Bernard W. Roos, On a class of singular second order differential equations with a

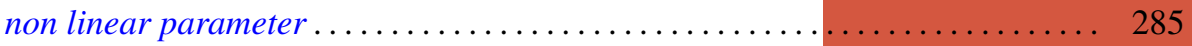

Tôru Saitô, Ordered completely regular semigroups . . . . . . . . . . . . . . . . 295

Edward Silverman, A problem of least area ....................... 309

Robert C. Sine, Spectral decomposition of a class of operators . . . . . . . . . 333

Jonathan Dean Swift, Chains and graphs of Ostrom planes . . . . . . . . . . . 353

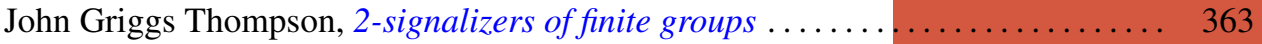

Harold Widom, On the spectrum of a Toeplitz operator . . . . . . . . . . . . . 365 